\title{
Risk profiles and corporate social responsibility for socially disadvantaged groups
}

\author{
Cosmin SERBANESCU \\ National Internal Control Institute, Bucharest, Romania \\ cosmin.serbanescu@incir.ro \\ Adrian VINTILESCU - BELCIUG \\ National Internal Control Institute, Bucharest, Romania, \\ Lacramioara CORCHES \\ Expert, Bucharest, Romania
}

\begin{abstract}
Developing a suitable mechanism to stimulate the effective redeployment of capital to social activities can be designed using the corporate social responsibility (CSR) concept. Informational asymmetry about the real state of social risks influences the effectiveness of allocations in social protection. Reducing information asymmetries can be achieved by providing the corporations with socially determined risk profiles based on predetermined patterns. Offering concrete lines of action following the risk profiles approach which to base investment decisions of companies in CSR can maximize the results of such a mechanism. In a previous study the authors have developed a theoretical model for determining the poverty risk profile. This study aims to present the practical application of the theoretical model and to provide comments on some errors. Hence, the authors analyzed Buzau county municipalities in presenting the highest risk level determined by the theoretical model and related causes and performed an impact assessment of an investment in CSR based on a model. Specifically, the authors evaluated the impact of reducing the risk of poverty for a suitable investment in CSR. In the second part of the study, the authors analyzed the types of errors that can be found in the municipalities risk profile model due to the granularity of the data. Thus, for the error of over-inclusion, the authors assessed social allocative efficiency at the community level using benchmarking analysis, Data Envelopment respectively and analyzed the data of the under-inclusion error in Buzau county villages. The paper aims to analyze the relative limits on quantitative models and risk of poverty and the practical implementation of these types of models in the development of corporate social responsibility.The study provides also a useful tool which can be made available to companies in order to increase the vulnerable groups' life quality and the satisfaction of shareholders, stakeholders and related parties following redeployments according to specific CSR mechanisms.
\end{abstract}

Keywords: corporate social responsibility, efficiency and effectiveness of social assistance programs, data envelopment, risk profile, business ethics.

\section{Introduction}

Government social protection programs are often seen as a kind of state's safety net for groups of people who have certain features that are detected under a selection process.

Social assistance redeployments programs related to poverty are addressed to people who need support. Mostly the risk is determined by membership in some communities with certain characteristics. (Ravallion and Chao, 1988)

Granting social assistance programs can be done mainly from the central level, only if there is evidence to undergo tests before granting or locally when the state only provides funding for such aid to local communities. 
Risk profiles are used in social assistance transfers of money from the state budget to local communities so poorer communities receive more money (for example: VAT redeployments).

Risk profiles can provide a global picture on poverty but also concrete group level intervention measures not only at the individual level, creating virtually externalities that enable sustainable development.

In Romanian public social assistance system there is an approach that the state is almost exclusively involved in combating poverty aid (welfare) without considering the strength of a capital transfer mechanism directly involving private companies.

Such mechanism for funding social assistance from private funds can be a major step in both reducing poverty, especially in reducing inequalities between social groups and, as such, helping to alleviate what Karl Marx referred to as capital greed.

Such a possibility of the existence of safety nets can be assured by companies through social responsibility.

CSR development can be achieved by increasing investor's interest which can be accomplished through a better knowledge of the specific situation of poverty in a particular area. Hence, having publicly and readily available municipalities risk profiles can be a useful tool.

Risk profiles can be made for administrative units, geographical areas, social groups based on relevant indicators such as unemployment, number of children, the proportion of Roma population, distance from a city, etc., and represents a quantitative model to quantify poverty in a certain group.

How can adequately be used these risk profiles in developing CSR policies and what are the limits of this type of models? This is the main goal of the study. The analysis is useful both to companies that desire to develop specific CSR projects but also to government officials that design public social assistance policies.

Let us imagine an extreme situation such as a natural disaster, when people easily see companies getting involved in self-help campaigns and also individual persons are much more active and become more sensitive. Why? Because, firstly, they know and react to a particular situation, and, secondly, because they realize that no matter how small their contribution might be, it has a big effect on the recipient of the donation.

Further developing the example above, having in mind the intention to create an effective mechanism for redistribution by CSR in poverty aid schemes, the authors have considered the two directions revealed above, respectively knowing the situation of disadvantaged groups in a certain area and the influence decision on capital by increasing its satisfaction thereof as donor (pure or impure) as a result of knowing the social effects of an investment in CSR.

As a consequence to these issues, the opportunity to know and identify who are the disadvantaged groups, the root causes, the real possibilities of action and also the quantification degree of reduction of poverty can lead to a more effective social assistance.

Corporate social responsibility (CSR) as a concept, is in public attention since 2001, when the European Commission published the Green Paper - "Promoting a European framework for corporate social responsibility".

So far, the experience of other European countries has shown that social responsibility is more than a program or campaign is a way to behave ethically and responsibly in all aspects of the business relationship (with employees, customers, shareholders, suppliers, environment and local communities). (Castka et. al., 2005)

There are several standards on this subject such as: 
$A A$ 1000: a standard produced by the Institute of Social and Ethical Accountability to improve the accountability and overall performance of organizations in order to favor a sustainable development path;

SA 8000: a social accountability standard, produced by Social Accountability International, concerning workers' rights and conditions, and child labor;

Corporate Governance frameworks: the guidance for effective corporate governance is provided by numerous codes and best practice guidelines - for instance by the Combined Code, the guidelines of the Organization for Economic Co-operation and Development (OECD) - Principles on Corporate Governance, and the Higgs Report;

This mechanism helps to efficiently redistribute the capital and practical policy involving voluntary transfers of capital by redistributing a portion of it towards social assistance. (Cox, 1987)

The involvement of companies in CSR projects, contributes to a relaxation of fiscal policies because some of the needs for social assistance coverage is satisfied by such mechanisms.

What is important to note is that this mechanism can alleviate the capital greed described by Karl Marx, by maximizing their satisfaction as pure or impure altruistic donors.

This maximization, was described in detail by the authors in the article: "Improving social assistance by using corporate social responsibility and risk profiles".

The companies involved in CSR projects have a satisfaction from the results obtained by being involved in charities that have as target group people in risk of social exclusion motivated by both the return on investment which has several components but also by pure and impure companies' altruism. (Cox, 1987, 1989)

Apparently CSR donations and actions are not Pareto optimal for companies, but a complex analysis of the above mentioned article outlines that companies benefit on the one hand from the rise of usefulness of such programs but also through growth of the indicators such as innovation, cost reductions, brand differentiation, long-term thinking, commitment to employees, tax incentives, cash flow resulted from revenue created. (Daisuke, 1999)

Practically, we can identify two main objectives of donors, given by the pure or impure character of the altruist:

i. altruism given by the investment in social responsibility to improve the living standards of social protection indicators;

ii. material interest by analyzing the factors that may influence the net added value for this type of social investments;

Those who provide social protection do not always have all the necessary data and, therefore, may not have regard to the main features of social groups.

To illustrate this statement we can bring into discussion the cases of cataclysm in a certain area that instantly mobilizes the tendency for donations and charity.

To overcome an informational asymmetry that gives companies the satisfaction of donations which involves increasing the utility of others, the companies should investigate to find out the tastes and preferences of the target audience, as an unsuitable or lower donation would bring less satisfaction than the envisaged one.

Reducing information asymmetry by using specific social assistance risk profiles available for potential investors can increase the effectiveness of interventions in social assistance and visibility of the effectiveness of the invested capital both in public and private sector. 
Governments are also interested in reducing information asymmetry that enable the knowledge of social issues by companies and also the possibilities for concrete action to respond to practical questions such as:

1. What are the most disadvantaged communities and what is their particular context?

2. What are the errors in the inclusion or non-inclusion of communities in high risk class (under-inclusion error or over-inclusion of the risk rating)?

PICBE | 866

3. What could be the action directions in which companies should be involved in CSR activities?

4. How it would cost the companies to involve in such campaigns and, especially, what is the reduction of social risk after the investment?

5. Can a national strategy in this regard be suitable that also includes tax facilities for companies?

\section{Description of the model used}

According to the risk profile described in the aforementioned article (Serbanescu et al., 2017), the authors defined a risk map based on the demographic and economic indicators related to each administrative unit (communes) from Buzau county.

Companies, analyzing the needs and possibilities of intervention from the above map can consider the investment opportunities in social responsibility campaigns using a personal cash flow analysis to take into account other components than the pecuniary ones such as the important effects and expected social benefits.

With reference to the above mentioned article we can conclude that the research has led to the creation of a model that stimulates the intervention using social responsibility based on economic efficiency, completed with other elements (interests of companies, pure altruism and derived from the information asymmetry) which, together with the determination of measures in social assistance based on an econometric model can facilitate the possibility of quantitative analysis on measures that can be taken in order to ensure an effective social assistance.

Therefore, the authors defined risk "percentage of incidents and coupons related to poverty" which includes the weight above the disadvantaged individuals (eligible under GD 799/2014) on which was also added the percentage of people in shelters (not covered by the abovementioned government decision).

The indicators taken into account in the theoretical study are based on the data related to Buzau county downloaded from the websites of specialized institutions such as the National Statistics Institute (NSI) and the General Directorate of Social Assistance and Child Protection (Child Protection) Buzau, as well as authors own assessments and analyzes. These indicators are: difficulty in reaching the city, total population, children percentage, percentage of poor people and people with disabilities, Roma ethnics, housing percentage, permanent occupied population percentage, unemployed percentage, Surface percentage, number of social workers percentage, weight of poverty related incidents and coupons.

In order to determine a model that shows the variation in the output indicator (risk of poverty) against the relevant indicators determined above, it was used the multivariate regression which used as explanatory variables unemployment, the difficulty of reaching the city, the percentage of children and the number of social workers.

The dataset of the model is presented in Annex 1.

It can be observed that regression is significant by the value of the coefficient $\mathrm{R}=$ 
0.98 but also that the explanatory variables are statistically significant by performing the statistical " $t$ " test ( $\mathrm{t}$ test for dependent samples).

Table 1: Dependence between the risk of social exclusion and other factors related to the community using multivariate regression.

Coefficients $(a, b)$

\begin{tabular}{|c|c|c|c|c|c|c|}
\hline \multirow[t]{2}{*}{ Model } & & \multicolumn{2}{|c|}{$\begin{array}{l}\text { Unstandardized } \\
\text { Coefficients }\end{array}$} & \multirow{2}{*}{$\begin{array}{c}\text { Standardized } \\
\text { Coefficients } \\
\text { Beta }\end{array}$} & \multirow[t]{2}{*}{$\mathbf{t}$} & \multirow[t]{2}{*}{ Sig. } \\
\hline & & B & Std. Error & & & \\
\hline & Difficulty in reaching the city & 010 & 002 & 244 & 5,357 & 000 \\
\hline & Percentage of children & 421 & ,048 & ,380 & 8,698 & 000 \\
\hline & Percentage of unemployed & 1,137 & ,126 & ,329 & 8,991 &, 000 \\
\hline & $\begin{array}{l}\text { Percentage of the number of } \\
\text { social workers }\end{array}$ & 34,681 & 12,448 & ,082 & 2,786 & 007 \\
\hline
\end{tabular}

PICBE | 867

Source: Authors' own research results.

The theoretical study mentioned above led to the definition of the following multivariate regression model:

share coupons related incidents and poverty $=0,01 \times$ difficulty in reaching the city + $0.421 \times$ children share weight $+1,137 \times$ weight of unemployment $+34,681 \times$ share of social workers number.

The importance of this result is given by quantification, based on the model, of the overall impact on the social indicator of poverty compared to other indicators.

For example, the decreased by 1 point of the difficulty of reaching the city generates a decrease of $0.1 \%$ of the risk of poverty. Therefore the involvement in CSR of an economic agent that would lead to the decrease in the difficulty of reaching the city implies that the company would know that, in this manner, can reduce the risk of poverty by $0.1 \%$.

In this study, there were chosen the following first municipalities of Buzau county at risk of poverty.

\section{Evaluating the possibilities of concrete intervention in Buzau county's municipalities with high poverty risk}

The authors chose to exemplify the model on the particular case of Buzau county because this county has a high percentage of unemployed persons, has a high unemployment rate, has a high share of the social assisted individuals and owns an underdeveloped infrastructure network.

Taking into consideration the above analysis for the top municipalities exposed to risk (where poverty is present), the authors presented below in addition to input and output indicators some specific directions and concrete action plan that can be undertaken.

To document this the authors used public studies and researches that characterize the respective communities and city halls websites, Buzau County Geopark Study: directions of socio-economic development - Geomedia Center; Sustainable Development Strategy and Action plan for Buzau County 2014 - 2020, field trips.

We present below the main strands in which companies can engage in corporate social responsibility actions in disadvantaged communities.

These strands were determined based on the input indicators importance and their value. 


\title{
Commune CSR related measures proposals Viperesti
}

Creating a system of exploitation of local products to support local producers by creating a network for the promotion and valorisation of local products (nuts, mushrooms, sponges, honey, apples, pears, plums) resulting from their cooperation with NGOs to support them in the entire process (from packaging, promotion, including to companies involved in CSR programs, to identify other potential customers). Organizing family planning campaigns with the following objectives: decreasing the number of unwanted pregnancies among young women, reducing the number of abandoned children; social reintegration, family and school for professional women; increasing the involvement of the local community. It will be provided free transportation to doctors or family planning clinics in order to achieve the above mentioned objectives. Developing a local residential center.

\begin{abstract}
Bisoca
With the support of an NGO can be created a briquettes and pellets factory. Raw materials can be almost free given that economic agents are dealing with difficulties in logging debris removal chip. Creating a system of exploitation of local products to support local producers by creating a network for the promotion and valorisation of local products (nuts, mushrooms, sponges, honey, apples, pears, plums) resulting from their cooperation with NGOs to support them in the entire process (from packaging, promotion including to companies involved in CSR programs, to identify other potential customers). Family planning in the village day care center or in the existing campus. Developing a local residential center.
\end{abstract}

\section{Braesti}

Given the great distance till the city and the fact that raw materials are abundant and are not adeqautely valued at the moment, an investment adapted to the needs of the local community is setting up a center for collecting and processing the milk from producers both in the village and in the neighboring municipalities. Collected and processed milk can be sold to another processor or to persons interested in organic products.

\section{Luciu}

Studies show that aquaculture food production sector has the fastest growth in a decade worldwide with a growth rate of $10 \%$ per year. We propose setting up a micro fish farm with the participation of the employees of companies involved in CSR programs.

\section{Mihailesti}

Subsidizing an NGO that specifically deals with Roma family planning at the existing multipurpose educational center in the community.

\section{The quantitative measurement of the impact of investment in CSR}

Investments in CSR projects such as those described above, will have influence on the output indicator, share coupons related incidents and poverty, respectively.

In this regard, we present in the table from Annex 2 the initial assessment of output and input indicators, before and after a specific investment, as analyzed above.

The evaluation after the investment in CSR was achieved by using in the regression equation new input variables such as estimated by the authors. 
It generates a matrix of the following type: initial risk profile assessment, possibilities for intervention, intervention cost, and subsequent risk assessment procedure. (Annex 2)

We consider that this analysis, if made available to companies interested in CSR reduces the information asymmetry and facilitates corporate involvement in initiating and financing such projects with social impact.

Also, CSR contributes to an effective redistribution from capital towards social and the efficiency of social assistance allocations that will also lead to an optimal taxation policy.

Extending this analysis to all communities in Romania would create a reduction in asymmetric information and would stimulate CSR investments.

In what follows, the authors have questioned this model's limits.

This study's approach has detailed the intervention scheme presented below in which are highlighted the government actions that would alter the companies investment in CSR projects.

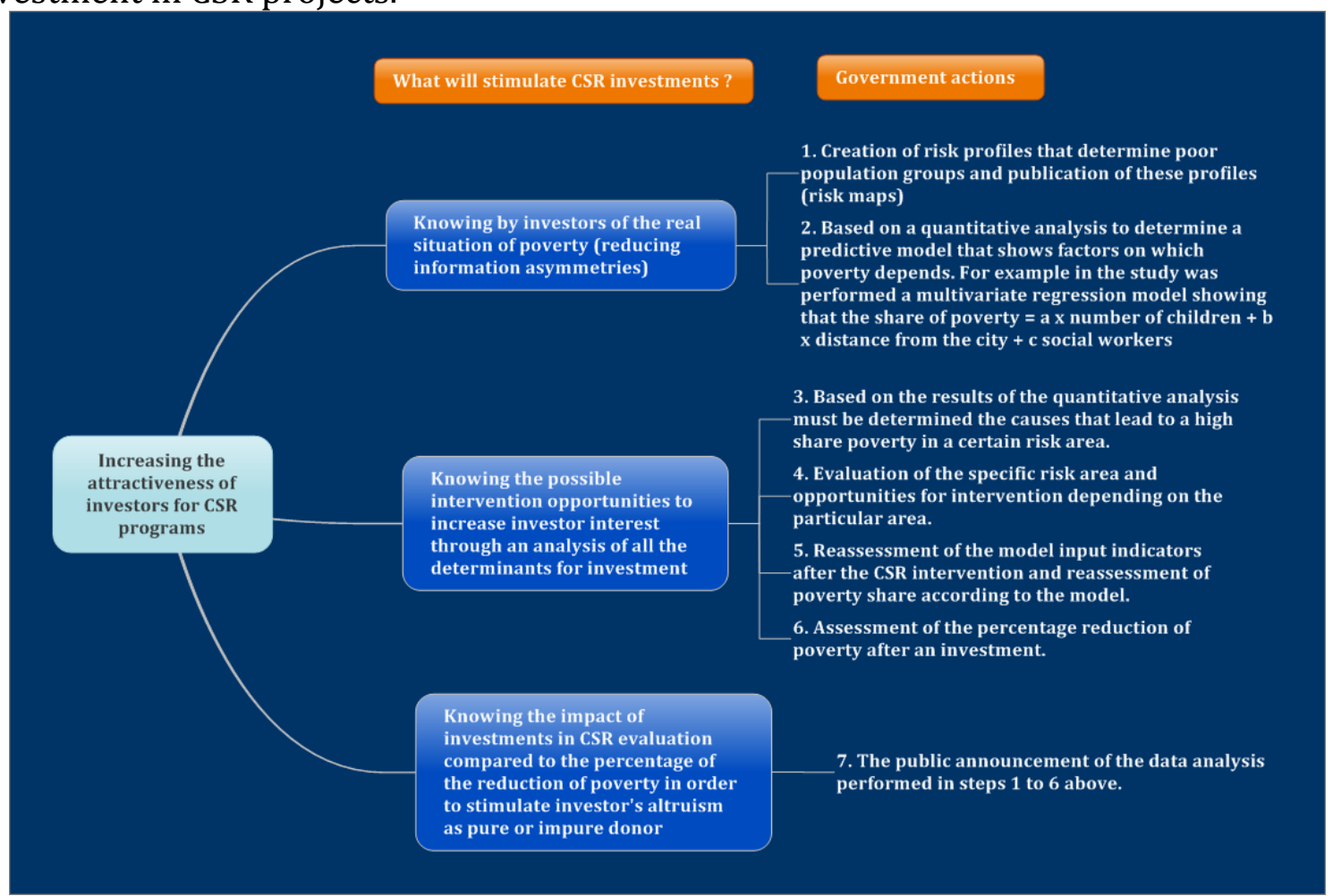

Figure 1. Government actions that would alter the companies investment in CSR projects.

Source: Authors' own research results.

The CSR intervention implies the following steps:

1. Determine the actual weight of poverty and creation of risk maps;

2. Determination of the relevant input indicators;

3. Evaluation based on a model of the weight of poverty calculated based on input indicators;

4. Determining the model errors;

5. Assessment of cases resulting from input indicators that lead to a high degree of poverty;

6. Evaluation of investment opportunities in the region;

7. Designing a possible investment based on opportunities that influence the input indicators; 
8. Quantification of the influence on output indicators in case of making the investment;

9. Reassessment of the output indicator (poverty weight) depending on reperformed input indicators;

10. Determination of poverty reduction degree (poverty level after intervention / degree of poverty before intervention);

11. Publication of these data.

PICBE | 870

The above described steps are detailed in Annex 2.

\section{Evaluation of model errors}

\section{Over-inclusion error related to poverty risk profile}

The authors have questioned whether poverty as defined for each commune is given by the inefficient use of resources.

Thus, there is a high share in the overall context of poverty although it should not be. Basically it is the error of over-inclusion which refers to the inclusion in the group of socially assisted persons or individuals who should not be included.

To determine the possibilities of error we conducted a performance comparative analysis using Data Envelopment (DEA).

DEA analysis is a nonparametric method used in research projects and economics for estimating production frontiers. (Farrell, 1957)

It is used to empirically measure the productive efficiency of decision-making units, communes in our case (or DMU).

Although DEA has a strong link with production theory in economics, the instrument is used for benchmarking in operations management, in case there is selected a set of measures to compare operations performance. (Wade et al., 2014)

Some of DEA's advantages are: (Coelli et al., 1998)

a. no need to specify an explicit mathematical form;

b. capable of handling multiple inputs and outputs;

c. can be used with any input-output measurement;

Some of DEA's disadvantages are:

a. results are sensitive to the inputs and outputs selection;

b. the number of effective frontier companies tends to increase with the number of inputs and outcome variables;

In this analysis we considered as output variable the poverty share coupons and as input variables the households share, the share of the employed stable population, the share of unemployed population, the share of population relative to the surface, the share of basic funding of school education units, and the share of income tax collected in the year preceding the year of assessment.

In the study we used output oriented DEA CRS method and we calculated the efficiency frontier.

Values close to 1 indicate that at a given economic and regional context there are more socially assisted persons which in our case implies a bigger error of over-inclusion that has to be analyzed by social inspection as it may be the case of an inefficient management of social assistance benefits.

For the communes analyzed in the study and which present a high risk of poverty we have plotted the technical efficiency (TE) indicator compared to the poverty indicator as output variable.

Thus, in case of communes that have an increased (TE) indicator, we believe that CSR investment options require some caution due to the local management. 


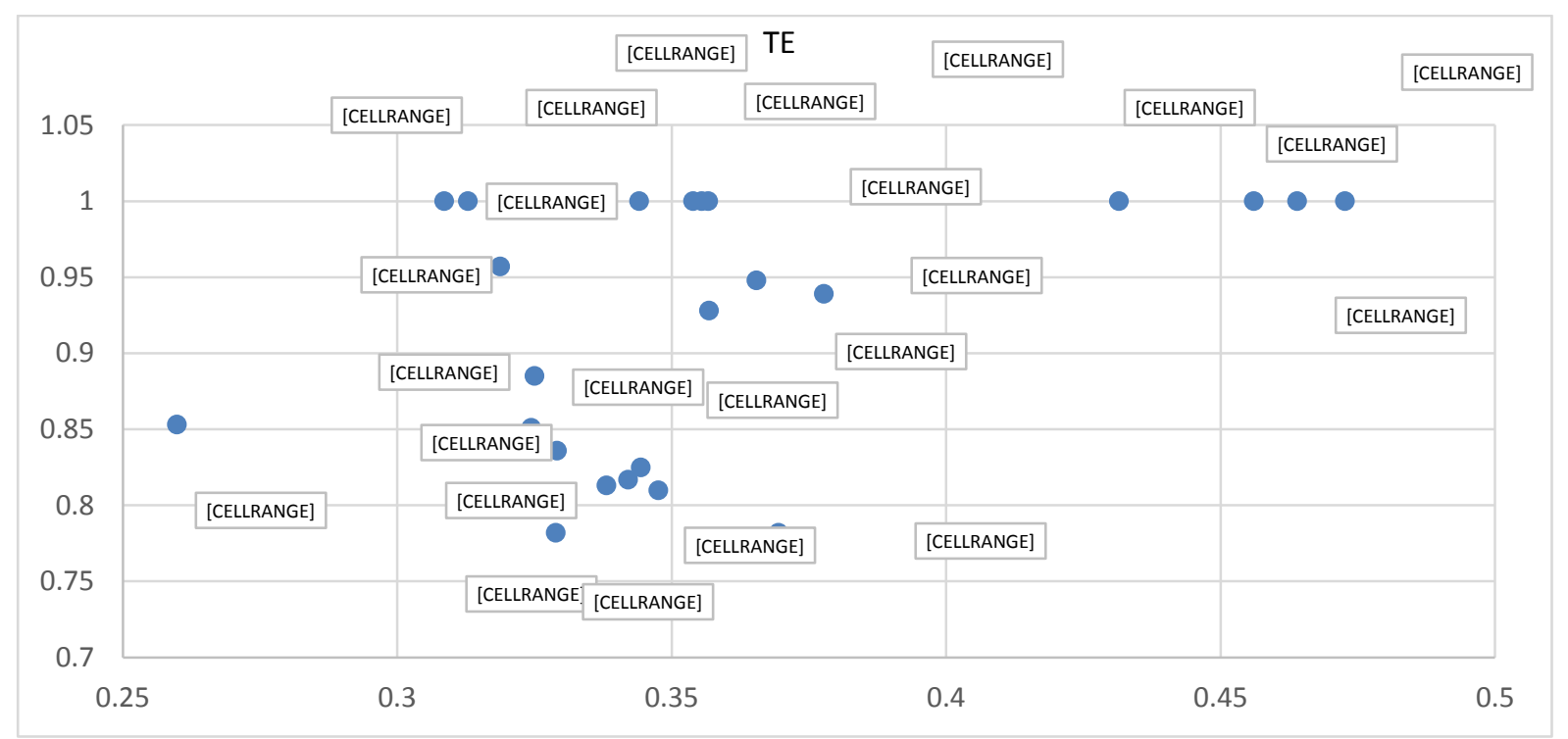

PICBE | 871

Figure 2: Over-inclusion error analysis using Data Envelopment.

Source: Authors' own research results.

\section{Under-inclusion error related to the poverty risk profile}

This error represents the non-inclusion in the risk profile of some communities which had to be included in the respective case of increasing granularity (for example: a deeper analysis from the commune level to the village level).

The authors have completed the theoretical study at the village level and assessed the poverty risk for Buzau county communes.

The table below shows the top ten villages from Buzau county with the highest poverty percentage.

Table 2. Analysis of the under-inclusion error.

\begin{tabular}{l|l|r|}
\multicolumn{1}{c|}{ COMMUNE } & \multicolumn{1}{|c|}{ VILLAGE } & $\begin{array}{c}\text { RISK } \\
\text { EVALUATION }\end{array}$ \\
\hline Bisoca & Sarile & $58.5769 \%$ \\
\hline Patarlagele & Manastirea & $49.0005 \%$ \\
\hline Mihailesti & Margineanu & $48.5118 \%$ \\
\hline Scortoasa & Grabicina de Jos & $47.8621 \%$ \\
\hline Magura & Ciuta & $47.3694 \%$ \\
\hline Luciu & Luciu & $42.2088 \%$ \\
\hline Naeni & Varf & $41.0163 \%$ \\
\hline Viperesti & Tronari & $40.9289 \%$ \\
\hline Manzalesti & Valea Cotoarei & $40.2309 \%$ \\
\hline Scortoasa & Golu Grabicina & $39.9662 \%$ \\
\hline Tisau & Padureni & $39.3336 \%$ \\
\hline & Source: authors' own research results.
\end{tabular}

Therefore, as it can be seen from the table above, in Patarlagele town there is a village with a high poverty rate of nearly $50 \%$ although the poverty risk for the territorial administrative units is much smaller.

Manastirea village is a remote village near the town Patarlagele where access is very difficult. In this particular case some CSR actions should be taken in order to assure the transportation. 


\section{Conclusion}

The study provided a risk profile and specific intervention measures for combating poverty in Buzau county, which can be made available to companies in order to adequately address social exclusion.

Corporations, being aware of a needs map, the intervention measures and assessing the impact of the proposed measures, can analyze the investment opportunity in social responsibility projects, incorporating in the cash flow analysis other components than just the financial ones.

Thus, this mechanism can effectively increase the efficiency of social assistance provided to adequately combat poverty by redistributing direct corporate income toward social assistance.

The research led to the development of concrete proposals and measures that could foster active intervention using CSR, increasing the efficiency and redistribution policy that allows companies to assess the economic efficiency, corroborated with other elements (corporations own interests, pure altruism and derived from informational asymmetry).

The study also analyzes the errors of over-inclusion and under-inclusion related to poverty risk profiles.

The over-inclusion error analysis reveals the impact of stakeholders' decisions in the risk profiles models used.

The under-inclusion error analysis reveals that if there is an increasing granularity in determining the risk profiles the accuracy of the model increases.

Model's limitation is given by the village-level heterogeneity, which can alleviate the increasing granularity of data. Likewise, the proposed measures allow for standardization that facilitates an efficient analysis for companies interested in specific CSR projects.

\section{References}

Ravallion, M. (1988) and Chao, K. (1988). Targeted Policies for Poverty Alleviation under Imperfect Information: Algorithms and Applications. Mimeo, Australian National University.

Dr. Castka, P., Dr. Bamber, C., and Professor Sharp, J.M. (2005). Implementing Effective Corporate Social Responsibility and Corporate Governance. Business Information (BSI).

Cox, D. (1987). Motives for Private Income Transfers. Journal of Political Economy, vol. 95(3), 508-46.

Cox, D. (1987), (1989). The Connection between Social Security and Private inter family transfers. Mimeo, Boston.

Daisuke, A. (1999). Ethics Compliance Management Systems. Ethics Compliance Standard 2000 (ECS2000), Business Ethics Research Project, Reitaku Centre for Economic Studies.

Serbanescu, C., Vintilescu, A., Corches, L. (2017). Efficiency and effectiveness in social assistance using corporate social responsibility and the risk profile. Romanian National Internal Control Institute study.

Farrell, M.J. (1957). The Measurement of Productive Efficiency. Journal of the Royal Statistical Society, 120(3), 253-281.

Wade D. Cook, Kaoru, Tone and Joe, Zhu (2014). Data envelopment analysis: Prior to choosing a model. Omega, 44,(C). 
Coelli, T., Rao, D.S.P. \& Battese, G.E. (1998). An Introduction to Efficiency and Productivity Analysis. Boston, MA: Kluwer Academic Publishers.

Government Order no. 799/2014 issued by the Romanian Government regarding the implementation of the operational program to help disadvantaged people.

Buzau County Geopark Study, directions of socio-economic development, Geomedia Center, University of Bucharest, 2007.

Sustainable Development Strategy and Action Plan for Buzau County 2014 - 2020, Buzau County Council, 2016.

www.insse.ro/cms/ (accessed on December 31st, 2016).

www.dgaspc-Buzau.ro/studiianalize/ (accessed on December 31 st 2016 )

Annex 1. The dataset of the model.

\begin{tabular}{|c|c|c|c|c|c|c|}
\hline Comuna & $\begin{array}{l}\text { dificultate } \\
\text { ajungere } \\
\text { oras }\end{array}$ & $\begin{array}{l}\text { pondere } \\
\text { copii }\end{array}$ & $\begin{array}{l}\text { pondere } \\
\text { POPULATIA_STAB } \\
\text { ILA_OCUPAT }\end{array}$ & $\begin{array}{l}\text { pondere } \\
\text { SOMERI }\end{array}$ & $\begin{array}{l}\text { pondere } \\
\text { NUMAR } \\
\text { ASISTENT } \\
\text { SOCIALI } \\
\end{array}$ & $\begin{array}{l}\text { pomdere } \\
\text { incidente si } \\
\text { cupoane } \\
\text { calculate } \\
\text { dupa modelul } \\
\text { econometric }\end{array}$ \\
\hline LUCIU & 8 & 0.25623762 & 0.315643564 & 0.18970297 & 0.00039604 & 0.417303366 \\
\hline VIPEREȘTI & 6 & 0.30816993 & 0.509803922 & 0.149673203 & 0.000980392 & 0.393918954 \\
\hline BISOCA & 9 & 0.32444627 & 0.634536505 & 0.10295324 & 0.000820345 & 0.372100082 \\
\hline MĂGURA & 5 & 0.27239959 & 0.3130793 & 0.157569516 & 0.000514933 & 0.36169516 \\
\hline BRĂEȘTI & 9 & 0.30305839 & 0.528730306 & 0.111677479 & 0.000463392 & 0.360635774 \\
\hline LARGU & 7 & 0.20946416 & 0.212943633 & 0.129436326 & 0.001391788 & 0.353622129 \\
\hline RÎMNICELU & 4 & 0.38051333 & 0.551457762 & 0.109892848 & 0.00049838 & 0.342428607 \\
\hline PĂNĂTĂU & 8 & 0.20639148 & 0.454505104 & 0.137594319 & 0.000443853 & 0.338728806 \\
\hline NĂENI & 9 & 0.27839506 & 0.436419753 & 0.092592593 & 0.000617284 & 0.333890123 \\
\hline BUDA & 8 & 0.25159835 & 0.459195186 & 0.111320045 & 0.000376081 & 0.325536668 \\
\hline MIHĂILEȘTI & 3 & 0.28514513 & 0.385315879 & 0.132612408 & 0.000569152 & 0.320565168 \\
\hline BOZIORU & 9 & 0.21713729 & 0.524829601 & 0.088607595 & 0.00097371 & 0.315930867 \\
\hline CHILIILE & 9 & 0.14705882 & 0.465397924 & 0.08650519 & 0.001730104 & 0.310269896 \\
\hline CĂNEȘTI & 8 & 0.2116129 & \begin{tabular}{l|l|} 
& 0.4 \\
\end{tabular} & 0.083870968 & 0.001290323 & 0.3092 \\
\hline BOLDU & 7 & 0.21206226 & 0.524805447 & 0.114785992 & 0.000486381 & 0.306658074 \\
\hline SCORȚOASA & 9 & 0.25019099 & 0.361344538 & 0.071428571 & 0.000763942 & 0.303038961 \\
\hline $\begin{array}{l}\text { MOVILA } \\
\text { BANULUI }\end{array}$ & 6 & 0.25290323 & 0.415913978 & 0.101935484 & 0.000430108 & 0.297289462 \\
\hline SĂRULEȘTI & 9 & 0.23717949 & 0.514423077 & 0.068108974 & 0.000801282 & 0.295081731 \\
\hline CĂTINA & 6 & 0.22899729 & 0.49232159 & 0.087172538 & 0.000903342 & 0.286851852 \\
\hline ODĂILE & 7 & 0.1988024 & 0.574850299 & 0.080239521 & 0.001197605 & 0.286462275 \\
\hline ROBEASCA & 5 & 0.2526725 & 0.514091351 & 0.073858115 & 0.000971817 & 0.274055394 \\
\hline CISLĂU & 5 & 0.24367542 & 0.442720764 & 0.092840095 & p.000238663 & 0.266423628 \\
\hline MîNZĂLEȘTI & 9 & 0.26104066 & 0.619151727 & 0.035417578 & 0.000437254 & 0.255332313 \\
\hline
\end{tabular}

Source: Authors' own research results. 
Annex 2. The initial assessment of output and input indicators, before and after a specific investment as analyzed above.

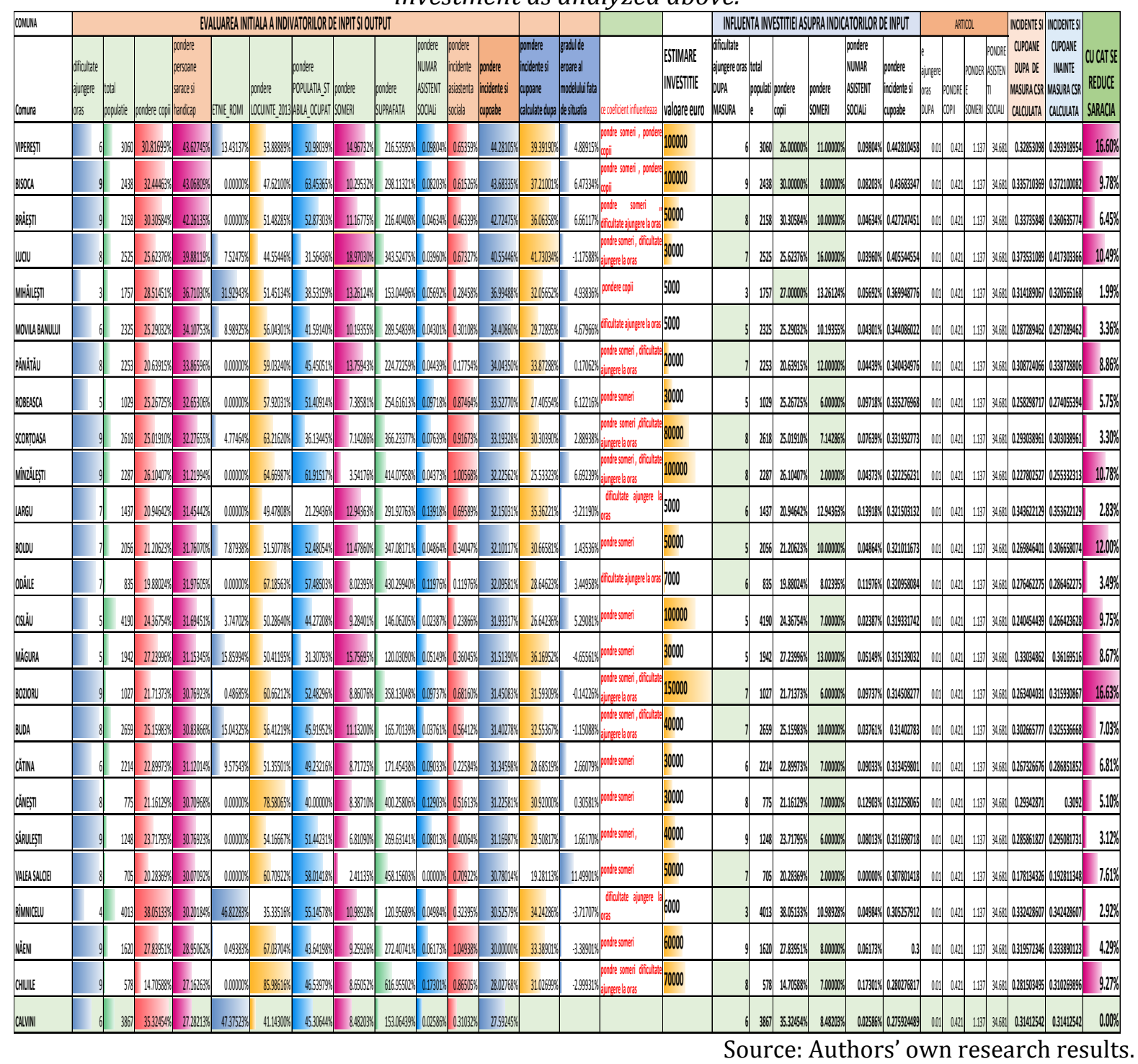

